\title{
Clinical outcome of root caries restorations using ART and rotary techniques in institutionalized elders
}

\section{Alberto Carlos CRUZ GONZALEZ(a) Dairo Javier MARÍN ZULUAGA(b)}

(a) Universidad Nacional de Colombia, Facultad de Odontología, Posgrado de Rehabilitación Oral, Bogotá, Colombia.

(b) Universidad Nacional de Colombia, Facultad de Odontología, Posgrado de Rehabilitación Oral, Bogotá, Colombia.

Declaration of Interests: The authors certify that they have no commercial or associative interest that represents a conflict of interest in connection with the manuscript.

Corresponding Author: Dairo Javier Marín Zuluaga E-mail: dimarinz@unal.edu.co

DOI: 10.1590/1807-3107BOR-2016.vol30.0063

Submitted: Jul 11, 2015

Accepted for publication: Sep 22, 2015

Last revision: Mar 29, 2016

\begin{abstract}
The aim of this study was to compare the clinical performance of root caries restorations after a six-month period using two methods, a conventional technique with rotary instruments and an atraumatic restorative technique (ART), in an institutionalized elderly population in the city of Bogotá, Colombia. Root caries represents a multifactorial, progressive, chronic lesion with softened, irregular and darkened tissue involving the radicular surface; it is highly prevalent in the elderly, especially in those who are physically or cognitively impaired. A quasi-experimental, double-blind, longitudinal study was carried out after cluster randomization of the sample. Two different experienced dentists, previously trained, performed the restorations using each technique. After six months, two new investigators performed a blind evaluation of the condition of the restorations. The results showed a significantly higher rate of success $(92.9 \%)$ using the conventional technique ( $p$ 0.03). However, we concluded that ART may have been the preferred technique in the study population because $81 \%$ of those restorations survived or were successful during the observation period.
\end{abstract}

Keywords: Root Caries; Dental Atraumatic Restorative Treatment; Glass Ionomer Cements; Aged.

\section{Introduction}

The number of elderly individuals who preserve their natural teeth, and the number of natural teeth preserved in each elderly individual, are increasing. ${ }^{1}$ Throughout their lives, the elderly accumulate oral pathologies and dental treatments; therefore, they present more complex situations to the dentist. ${ }^{2}$ Many elderly individuals reside in geriatric institutions and are more vulnerable to diseases of dental origin. This is because they have limited access to dental healthcare services, physical or cognitive impairments, and, compared with those living in their homes, poorer oral hygiene and increased oro-dental diseases such as crown and root caries, which constitute an unsolved health problem. . $^{3,4,5,6}$

Root caries is a multifactorial, progressive, chronic lesion that exhibits softened, irregular and darkened tissue on the radicular surface and involves cementum, dentin or enamel in the proximity of the cementoenamel junction with an initial appearance on the root surface. ${ }^{7}$ Crown and root caries constitute one of the main causes of tooth loss in elderly individuals and 
represent one of the most important health problems in this population, with a prevalence between $27 \%$ and $66.7 \% .8,9,10,11,12$

Different alternatives in the management of root caries have been suggested, ranging from conventional removal with rotary instruments and sealing with polymer materials to the use of fluoride toothpastes and other remineralizing agents. ${ }^{13}$ The atraumatic restorative technique (ART) is an alternative technique in which the softened tissue of the lesion is removed with a manual instrument and is sealed with an adhesive material such as glass ionomer cement. ${ }^{14,15}$ This technique is advantageous in that only the softened tissue is removed, the cavity is prepared according to the shape of the lesion, anesthesia is normally unnecessary, electrical or hydraulic equipment is not required, and it has a low cost and decreases patient anxiety. ${ }^{16}$ However, with this technique, there are some limitations related to the filling material: the restoration is difficult to polish, the restorative materials have a sub-optimal resistance to oral fluids, there is a risk of leakage and compound cavity fracture, and the esthetics are limited. Thus, to perform ART, cavities should present certain criteria, such as extension to the dentin, ability to be removed with a manual instrument, and lack of a history of pain, fistula or pulp exposure. ${ }^{6,15}$ Glass ionomer cement is a good restorative agent for this technique because it has the following advantages: acceptable biocompatibility; good physical-mechanical properties; good adherence to dental substrates (enamel, dentin and cementum); minimal polymerization shrinkage; isolation, thermal and electrical properties; good marginal sealing properties; easy application; anti-cariogenic properties from fluoride release; and antimicrobial activity. ${ }^{17}$ In contrast, glass ionomer cements present some limitations, as mentioned above.

The purpose of the present study was to compare the clinical performance of root caries restorations using a conventional technique with a rotary instrument or ART in an elderly group of participants living in geriatric institutions in the city of Bogotá, Colombia.

\section{Methodology}

The study population consisted of elderly individuals aged older than 60 years who were living in nursing homes in the city of Bogotá, Colombia and were diagnosed with root caries. The Health Secretary of Bogotá provided a list of 225 geriatric institutions in the city; 165 were contacted and 23 consented to participate in the study ( $14 \%$ response). To determine the size of the sample, a difference in the survival rate of $15 \%$ or higher was considered to be clinically significant. To achieve $80 \%$ power and $5 \%$ statistical significance, an estimate of 80 restorations for each group was required.

The study protocol was approved by the Ethics Committee of the School of Dentistry of the Universidad Nacional de Colombia (approval protocol no. CIE 00194-12), and each study participant or responsible relative signed an informed consent form. A portable dental chair with illumination was used for clinical examinations in the nursing homes. The soft plaque was recorded according to the debris index (Greene and Vermillion, OHI-S index). ${ }^{18}$ Subsequently, dental plaque and calculus were removed using a manual instrument. The diagnosis was performed according to the International Caries Detection and Assessment System (ICDAS) criteria for the visual inspection of root caries. ${ }^{19}$ A root caries case was defined as the softening of the root dentin to a depth of $0.5 \mathrm{~mm}$ or greater as detected using a WHO dental probe. The teeth indicated for extraction or those with lesions close to the dental pulp and pain symptomatology were excluded from the study. A series of random numbers was used to fabricate sealed envelopes that were only opened for the random allocation of the participants to each working group (ART or conventional technique with rotary instruments). The decayed roots of each participant were filled using the same technique according to the assigned group.

To standardize the procedures, the two experienced dentists (who performed all the restorations of the study) performed 10 restorations using rotary instruments (conventional technique) and 10 restorations using manual instruments (ART technique). After this, the dentists were randomly chosen to perform all of the restorations using one of the two techniques. ART was performed using only manual instrumentation to remove decayed tissue, whereas the conventional technique was performed 
using a high-speed hand-piece with irrigation and round diamond burs of different diameters. Cotton rolls and a retraction cord were used to obtain relative isolation of the operative field. Once the cavity was shaped, $2 \%$ chlorhexidine (Clorhexol $0.2 \mathrm{~g} / 100 \mathrm{~mL}$; Farpag ${ }^{\circledR}$, Bogota, Colombia) was applied with a cotton swab for one minute, ${ }^{20,21}$ and the cavity was dried and sealed with a glass ionomer cement modified with light-curing composite resin (Vitremer ${ }^{\mathrm{TM}}{ }^{\circledR}, 3 \mathrm{M}$ ESPE, Seefeld, Germany) following the manufacturer's instructions. The material was placed in the cavity using a dispensing gun, and a celluloid matrix was used to shape the root prior to polymerization. Restorations were polished on the same appointment. For the ART technique, interproximal metal and paper strips were used, and the conventional restorations were polished with fine-grain diamond burs and Sof-Lex discs $\left(3 \mathrm{M}\right.$ ESPE $\left.{ }^{\circledR}\right)$ using a micromotor $\left(\mathrm{MTI}^{\circledR}\right.$, Stará Turá, Eslovaquia) and a contra-angle $\left(\mathrm{NSK}^{\circledR}{ }^{\circledR}\right.$, Shinagawa, Tokyo, Japón).

After six months, the condition of the restorations was assessed by two different prosthodontists, without awareness of the technique that was performed in each participant. The evaluation criteria were established according to the studies of Frencken et al.,22 Bayne and Schmalz, ${ }^{23}$ Cvar and Ryge, ${ }^{24}$ and Lo et al. ${ }^{25}$ (Table 1).

The data were gathered in a database created for the study and analyzed by a statistician. The statistician was blinded to the information on the type of treatment performed in each group. For the analysis of the plaque index, the oral hygiene of participants was classified as "optimal" when the values of the debris index were between 0.0 and 1.0, "regular" when the values of the index were between 1.1 and 2.0, and "poor" when the values of the index were over 2.1.

Initially, a descriptive analysis of the variables of the study was performed. A test of the proportional differences was carried out (Excel, Microsoft Office $2013^{\circledR}$, Redmond, USA) to determine the significant differences among the compared variables. Comparison of both techniques regarding technique failure, the quality of oral hygiene and the presence of antagonists were evaluated using the chi-squared test (SPSS, Chicago, USA). For the analysis of performance, the restorations were grouped into three categories as follows: "successful" if the restoration was present and without marginal defects or secondary caries; "survival" if the restoration was present with a

Table 1. Six-month assessment criteria of the restorations.

\begin{tabular}{|c|c|c|c|}
\hline Variable & Conceptual Definition & \multicolumn{2}{|c|}{ Operational definition } \\
\hline \multirow{2}{*}{$\begin{array}{l}\text { Presence of the } \\
\text { restoration }\end{array}$} & \multirow{2}{*}{ Restoration present in oral cavity } & \multicolumn{2}{|c|}{ Present } \\
\hline & & \multicolumn{2}{|c|}{ Absent } \\
\hline \multirow{9}{*}{$\begin{array}{l}\text { Condition of the } \\
\text { restoration }\end{array}$} & \multirow{3}{*}{$\begin{array}{l}\text { Evaluation of the margin of the restoration performed with the } \\
\text { tip of a periodontal probe }(0.5 \mathrm{~mm}) \text {, confirmed if it penetrates. }\end{array}$} & \multicolumn{2}{|c|}{ Adapted: without defect } \\
\hline & & \multicolumn{2}{|c|}{ Defect $<0.5 \mathrm{~mm}$} \\
\hline & & \multicolumn{2}{|c|}{ Defect $>0.5 \mathrm{~mm}$} \\
\hline & \multirow{2}{*}{$\begin{array}{l}\text { Change in the coloration of the surface of the restoration. } \\
\qquad \text { Visual criterion. }\end{array}$} & \multirow{2}{*}{ Pigmentation } & Yes \\
\hline & & & No \\
\hline & \multirow{2}{*}{$\begin{array}{l}\text { The surface is determined to be smooth or rough when sliding } \\
\text { the periodontal probe over the surface. Tactile criterion. }\end{array}$} & \multirow{2}{*}{ Texture of the surface } & Smooth, polished \\
\hline & & & Sandy, porous \\
\hline & \multirow{2}{*}{$\begin{array}{c}\text { With a visual and tactile method, the margins of the restoration } \\
\text { are confirmed to be continuous with the root surface. }\end{array}$} & \multirow{2}{*}{ Anatomical shape } & Continuous \\
\hline & & & Discontinuous \\
\hline \multirow{2}{*}{ Secondary caries } & \multirow{2}{*}{$\begin{array}{l}\text { Softened root dentin with the contact of the periodontal } \\
\text { probe on the margin of the restorative material. }\end{array}$} & \multicolumn{2}{|c|}{ Yes } \\
\hline & & \multicolumn{2}{|c|}{ No } \\
\hline \multirow{4}{*}{ Antagonist } & \multirow{4}{*}{$\begin{array}{c}\text { Presence of a natural or prosthetic tooth occluding with } \\
\text { the restored tooth. }\end{array}$} & \multicolumn{2}{|c|}{ Absent } \\
\hline & & \multirow{3}{*}{ Present } & Natural \\
\hline & & & Ceramic \\
\hline & & & Acrylic \\
\hline Oral hygiene & Simplified Oral Hygiene Index 18 & \multicolumn{2}{|c|}{ Debris index } \\
\hline
\end{tabular}


marginal defect of $0.5 \mathrm{~mm}$ or less and without secondary caries; and "failure" if the restoration was absent, if there was a marginal defect greater than $0.5 \mathrm{~mm}$, or if there were secondary caries.

\section{Results}

The present study included 75 elderly individuals from 23 geriatric institutions in the city of Bogotá with root caries: 36 women and 39 men aged between 60 and 101 years with a mean age of 74.9 years. A total of 174 restorations (73 with ART and 101 with the conventional technique) were performed. The average number of teeth was 8.4, ranging from 1 to 30. Fifty-two percent (90) of the restorations were performed in men, and $48 \%$ (84) in women. After six months, two evaluators examined the clinical performance of all of the restorations (Kappa $=0.909$ ).

The teeth were grouped by type to determine which were most affected, as follows: 81 lower anterior teeth $(48.5 \%), 31$ upper anterior teeth (18.5\%), 27 lower premolars (16\%), 11 upper premolars (6.5\%), 10 upper molars (6\%), and seven lower molars (4\%).

Regarding the distribution of the lesions according to dental surface, the vestibular surface was the most affected by root caries (38\%), followed by the proximal surfaces (33\% distal and 24\% mesial) and the lingual and palatal surfaces (5\%).

After six months, 64 participants were evaluated ( 32 men and 32 women) and 26 restorations (14.9\%) were lost. Seven participants changed geriatric institutions and were lost to follow-up, two died, and the two remaining participants were unreachable at the institution during the time of revision. A total of 148 restorations were evaluated, $64(43 \%)$ restorations using the ART and $84(57 \%)$ restorations using the conventional technique. The distribution of the restorations according to the number of surfaces was as follows: for the ART technique, $68(81 \%)$ restorations encompassed one surface, 15 (18\%) restorations included two surfaces, and one restoration involved three surfaces. For the conventional technique, 54 (84\%) restorations involved one surface, 9 (14\%) restorations included two surfaces, and one restoration encompassed four surfaces. A significantly higher number of secondary caries was observed in the ART group than in the conventional technique group $(p<0.001$; Table 2$)$.

There was a statistically significant difference between the groups regarding the clinical performance of the restorations. Approximately $81.3 \%$ of the ART restorations were survivors or were successful after six months (9.4\% and $71.9 \%$, respectively) compared to $92.9 \%$ of the conventional technique restorations (4.8\%, and $88.1 \%$, respectively). A significantly higher number of failed ART restorations $(p<0.03)$ and a lower number of successful ART restorations $(p<0.025)$ were observed compared to those of the conventional technique (Table 3).

The debris index showed a similar distribution in both treatment groups $(\mathrm{p}<0.65)$. For the ART group, there were 22,20 and 22 restorations in participants that

Table 2. Six-month assessment of the presence and condition of the restorations (\%).

\begin{tabular}{|c|c|c|c|c|}
\hline \multirow{2}{*}{ Condition } & & ART restorations & Conventional restorations & \multirow{2}{*}{$p$ value } \\
\hline & & $n=64$ & $\mathrm{n}=84$ & \\
\hline Present & & 75 & 88 & $p<0.078$ \\
\hline Absent & & 0 & 3.5 & - \\
\hline Adapted & & 72 & 88 & $p<1.98$ \\
\hline Defect $<0.5 \mathrm{~mm}$ & & 9 & 5 & $p<0.285$ \\
\hline Defect $>0.5 \mathrm{~mm}$ & & 19 & 3.5 & $p<1.99$ \\
\hline Pigmentation & Yes & 34 & 28 & $p<0.3$ \\
\hline \multirow[t]{2}{*}{ Anatomical shape } & $\begin{array}{c}\text { Continuous with root } \\
\text { anatomy }\end{array}$ & 59 & 72 & $p<0.16$ \\
\hline & Discontinuous & 41 & 28 & - \\
\hline \multirow{2}{*}{ Surface } & Smooth, polished & 75 & 75 & $p<0.74$ \\
\hline & Sandy, rough & 25 & 25 & - \\
\hline Secondary caries & Yes & 17 & 1 & $p<0.001$ \\
\hline
\end{tabular}


Table 3. Clinical performance of the restorations after six months.

\begin{tabular}{lcccc}
\hline Restorations & ART $n(\%)$ & $\begin{array}{c}\text { Conventional } \\
\mathrm{n}(\%)\end{array}$ & $\mathrm{p}$ value & Total \\
\hline Failures & $12(18.7)$ & $6(7.1)$ & $\mathrm{p}<0.03$ & 18 \\
$\begin{array}{l}\text { Survivors and } \\
\text { successfulness }\end{array}$ & $52(81.3)$ & $78(92.9)$ & $\mathrm{p}<0.025$ & 130 \\
Total & 64 & 84 & - & 148 \\
\hline
\end{tabular}

showed "poor" "regular", and "optimal" oral hygiene, respectively; this distribution was 23,30 and 31 for the conventional technique, respectively. There was no correlation between the failures in both restorative techniques and the quality of oral hygiene $(p<0.98)$.

Regarding the presence of the antagonist, 45 restorations from the ART group were performed in teeth that had an antagonist and 19 in teeth that did not; for the conventional technique, 45 restorations had an antagonist and 38 did not. When analyzing the type of antagonist, for ART, 11 were natural teeth and 34 were acrylic; for the conventional technique, 22 were natural antagonists and 23 were acrylic teeth. There was no correlation between the failures in both techniques and the presence of an antagonist. Of the six failed restorations using the conventional technique, half had an antagonist, while three did not. However, of the 12 failed restoration with the ART technique, 11 were performed in teeth with an antagonist, which was close to statistical significance $(p<0.07)$.

\section{Discussion}

Studies that assess ART for root caries of permanent teeth are rare. ${ }^{25,26,27}$ They are even less common in an institutionalized elderly population. The present study compared the clinical performance of root caries restorations performed using ART and a restorative technique using rotary instruments in an elderly population. A survival rate between $80 \%$ and $86 \%$ has been reported for ART restorations in permanent teeth after a 1- to 3-year follow-up. ${ }^{26}$ More specifically, for root caries in the elderly, the reported survival was $86.4 \%, 87 \%$ and $63 \%$ after a follow-up of 6, 12 and 24 months, respectively. ${ }^{25,26,27}$ In the present study, the rate of success and survival was slightly lower than that reported previously $(81 \%$ at the 6-month follow-up).
A statistically significant difference was observed when comparing the failure of the restorative techniques, with $18.7 \%$ failure in ART and 7.1\% for the conventional technique. In contrast with these results, in 2006, Lo et al. ${ }^{25}$ conducted a study on a population similar to that used in our study and reported the lack of a significant difference in clinical performance when comparing both methods in 122 restorations (59 ART and 63 conventional restorations) using conventional and glass ionomer cement modified with composite resin. At the 12-month follow-up, nine ART restorations and six conventional restorations failed. ${ }^{25}$

The factors associated with the failure of ART reported in the literature include type of restorative technique, restorative material, operator, low frequency of tooth brushing and high levels of dental plaque. ${ }^{28}$, ${ }^{29}$ Regarding the restorative material, a manual mixture of glass ionomer cement may incorporate air or generate changes in their properties if inadequate proportions are added. ${ }^{30}$ In the current study, the glass ionomer cement was manually mixed; however, it was applied to the cavity using the manufacturer's dispenser and a matrix to shape it to the root anatomy while confirming its adoption with a probe. The study by Ewoldsen et al. ${ }^{31}$ evaluated the mechanical properties of the glass ionomer in enamel and dentin when modifying the powder-liquid proportions (3.6:1) and showed significantly greater wear resistance and greater adherence to the tooth using glass ionomer cement modified with composite resin compared to that using conventional glass ionomer cement. Thus, the use of glass ionomer cement modified with composite resin is recommended to increase the rate of success of ART restorations, and for that reason, we used this material in the present study. An additional factor that might affect the long-term results of root restorations is the extent of the restoration. In the present study, the distribution of the root surfaces affected by the lesions was quite similar in both groups, as shown in the results.

In addition, operator-related factors may contribute to the failure of the restorations, and include incorrect clinical indications to perform the procedure, insufficient removal of decayed tissue, inadequate management of humidity, and poor manipulation of the restorative material..$^{22,32,33} \mathrm{In}$ an attempt to control 
these aspects in the present study, the operators were standardized prior to performing the restorations on the participants of the study.

There were more failures in the ART than in the rotary technique, and most of them were because of secondary caries. Uncooperative behavior in institutionalized elders leads to poorer oral hygiene and more caries. ${ }^{4}$ This could also exacerbate the incomplete removal of decayed tissue (especially when it is performed with manual instruments), which in the presence of high levels of dental plaque is a risk factor for secondary caries. Although the present study did not examine this factor, future work should investigate it to determine the role it may play in treatment failure. The use of a caries detector system when performing the ART technique might also help to achieve the complete removal of decayed tissue, thereby contributing to the success of the ART technique.

In the present study, the failure of the restorations was correlated with oral hygiene and the presence of an antagonist to the treated tooth, with a non-statistically significant association.

Oral hygiene may be related to the failure of ART root caries restorations in the elderly. ${ }^{27,28}$ Regarding the "poor" and "regular" debris index scores, eight cases of ART failed compared to 24 restorations with the same values of oral hygiene that showed no signs of failure. In addition, four restorations with an "optimal" oral hygiene score failed compared to 18 acceptable restorations. This indicated the irrelevant role of oral hygiene in the condition of the restorations during this follow-up period. The short follow-up time of the present study may explain the lack of association between the failure of restorations and deficient oral hygiene. To address the latter issue, Kemoli et al. ${ }^{34}$ reported in 2011 a correlation between a high plaque index and a higher risk of failure of restorations when assessing the plaque index of 648 temporary molars restored with ART in a 2-year follow-up; however, this relationship was not statistically significant.

The presence of a tooth opposing the tooth that receives a cervical filling might affect the long-term performance of the restoration due to the concentration of tensile forces in that area, which might produce failures of retention and the formation of marginal gaps. ${ }^{35}$ The six-month follow-up period of the current work might not be sufficient to evaluate this variable. In addition, elderly people might have natural, ceramic or acrylic antagonists to the tooth being restored or might not have antagonists. The examination of this aspect in relation to the clinical outcome of root caries restorations will facilitate clinical decision making.

Given the particular circumstances of the elderly institutionalized population, in which a high percentage of the population present physical or cognitive disorders that obstruct their oral hygiene habits, as well as obstructing their regular transfer to a dental office for conventional treatment. The use of alternative techniques such as ART, which was shown in the present study to have a high percentage of survival and success (81\%), may be an alternative to dental treatment at their residence, thus contributing to the improvement of their quality of life.

Some of the present study's limitations need to be discussed. The sample was not selected from all the nursing homes in Bogotá; we made contact with only 165 of the 225 geriatric institutions in the city, and only 23 of them consented to participate and thus constitute part of the sample. These institutions were considered to be representative of the population, but the sampling framework was not random. Thus, a potential selection bias cannot be ignored, although it was not apparent. Standardization of the dentists who performed the restorations was conducted, but intra-examiner reliability was not measured and could represent a source of potential bias. Finally, the use of the split mouth method is suggested for future works to reach a more balanced sample in the study groups.

\section{Conclusions}

Considering the conditions of the present study, the following conclusions can be made:

(1) A significantly higher number of failures in root caries restorations were observed with ART than with the conventional technique. Nevertheless, the high percentage of success and survival in the ART 
restorations indicates that the use of this technique is recommended in a similar study population.

(2) The conventional technique with rotary instrumentation continues to be the method of choice as long as the patient can visit a dental office or when a portable dental unit is available to perform the procedures at a geriatric institution.

\section{References}

1. Samson H, Strand GV, Haugejorden O. Change in oral health status among the institutionalized Norwegian elderly over a period of 16 years. Acta Odontol Scand. 2008;66(6):368-73. doi:10.1080/00016350802378654

2. De Visschere LM, van der Putten GJ, Vanobbergen JN, Schols JM, de Baat C; Dutch Association of Nursing Home Physicians. An oral health care guideline for institutionalised older people. Gerodontology. 2011;28(4):307-10. doi:10.1111/j.1741-2358.2010.00406.x

3. Matthews DC, Clovis JB, Brillant MG, Filiaggi MJ, McNally $\mathrm{ME}$, Kotzer RD, et al. Oral health status of long-term care residents-a vulnerable population. J Can Dent Assoc 2012;78:c3.

4. Marín Zuluaga DJ, Ferreira J, Gil-Montoya JA, Willumsen T. Oral health in institutionalised elderly people in Oslo, Norway and its relationship with dependence and cognitive impairment. Gerodontology. 2012;29(2):e420-6. doi:10.1111/j.1741-2358.2011.00490.x

5. Philip P, Rogers C, Kruger E, Tennant M. Caries experience of institutionalized elderly and its association with dementia and functional status. Int J Dent Hyg. 2012;10(2):122-7. doi:10.1111/j.1601-5037.2011.00525.x

6. Tascón J. Atraumatic restorative treatment to control dental caries: history, characteristics, and contributions of the technique. Rev Panam Salud Publica. 2005;17(2):110-5. Spanish. doi:10.1590/S1020-49892005000200007

7. Zhang W, McGrath C, Lo EC. A comparison of root caries diagnosis based on visual-tactile criteria and DIAGNOdent in vivo. J Dent. 2009;37(7):509-13. doi:10.1016/j.jdent.2009.03.009

8. Saunders RH Jr, Meyerowitz C. Dental caries in older adults. Dent Clin North Am. 2005;49(2):293-308. doi:10.1016/j.cden.2004.10.004

9. Banting DW. Epidemiology of root caries. Gerodontology. 1986;5(1):5-11. doi:10.1111/j.1741-2358.1986.tb00377.x

10. Fure $S$. Ten-year cross-sectional and incidence study of coronal and root caries and some related factors in elderly Swedish individuals. Gerodontology. 2004;21(3):130-40. doi:10.1111/j.1741-2358.2004.00025.x

11. Imazato S, Ikebe K, Nokubi T, Ebisu S, Walls AW. Prevalence of root caries in a selected population of

\section{Acknowledgements}

We thank COLCIENCIAS for the Young Researcher Scholarship-Internship Program award given to Alberto Carlos Cruz González. We also thank the participating investigators Lilia I. Lázaro and Luz N. Ovalle for their contributions during the collection of the data.

older adults in Japan. J Oral Rehabil. 2006;33(2):137-43. doi:10.1111/j.1365-2842.2006.01547.x

12. Mamai-Homata E, Topitsoglou V, Oulis C, Margaritis V, Polychronopoulou A. Risk indicators of coronal and root caries in Greek middle aged adults and senior citizens. BMC Public Health. 2012;12(1):484. doi:10.1186/1471-2458-12-484

13. Hara AT, Magalhães CS, Serra MC, Rodrigues Jr AL. Cariostatic effect of fluoride-containing restorative systems associated with dentifrices on root dentin. J Dent. 2002;30(5-6):205-12. doi:10.1016/S0300-5712(02)00017-9

14. Zanata RL, Navarro MFL. International symposium of Atraumatic Restorative Treatment: proceedings of the symposium held on 4-5 June 2004 at Bauru Dental School, Bauru, Sao Paulo, Brazil. J Appl Oral Sci. 2006;14 Spec No:1. doi:10.1590/S1678-77572006000700001

15. Navarro MFL, Modena KCS, Freitas MCCA, Fagundes

TC. Transferring ART research into education in Brazil. J Appl Oral Sci. 2009;17 Spe No:99-105. doi:10.1590/S1678-77572009000700017

16. Navarro MFL. Introduction to the symposium. Two decades of ART: success through research. J Appl Oral Sci. 2009;17 Spe No:76-7. doi:10.1590/S1678-77572009000700013

17. Molina GF, Cabral RJ, Frencken JE. The ART approach: clinical aspects reviewed. J Appl Oral Sci. 2009;17 Spe No:89-98. doi:10.1590/S1678-77572009000700016

18. Greene JC, Vermillion JR. The Simplified Oral Hygiene Index. J Am Dent Assoc. 1964;68(1):7-13. doi:10.14219/jada.archive.1964.0034

19. Ismail AI, Sohn W, Tellez M, Amaya A, Sen A, Hasson H, et al. The International Caries Detection and Assessment System (ICDAS): an integrated system for measuring dental caries. Community Dent Oral Epidemiol. 2007;35(3):170-8. doi:10.1111/j.1600-0528.2007.00347.x

20. Emilson CG. Susceptibility of various microorganisms to chlorhexidine. Scand J Dent Res. 1977;85(4):255-65.

21. Bowden GH, Ekstrand J, McNaughton B, Challacombe SJ. Association of selected bacteria with the lesions of root surface caries. Oral Microbiol Immunol. 1990;5(6):346-51. doi:10.1111/j.1399-302X.1990.tb00439.x

22. Frencken JE, Makoni F, Sithole WD. ART restorations and glass ionomer sealants in Zimbabwe: survival after 3 
years. Community Dent Oral Epidemiol. 1998;26(6):372-81. doi:10.1111/j.1600-0528.1998.tb01975.x

23. Bayne SC, Schmalz G. Reprinting the classic article on USPHS evaluation methods for measuring the clinical research performance of restorative materials. Clin Oral Investig. 2005;9(4):209-14. doi:10.1007/s00784-005-0017-0

24. Cvar JF, Ryge G. Reprint of criteria for the clinical evaluation of dental restorative materials. 1971. Clin Oral Investig. 2005;9(4):215-32. doi:10.1007/s00784-005-0018-z

25. Lo EC, Luo Y, Tan HP, Dyson JE, Corbet EF. ART and conventional root restorations in elders after 12 months. J Dent Res. 2006;85(10):929-32. doi:10.1177/154405910608501011

26. Amorim RG, Leal SC, Frencken JE. Survival of atraumatic restorative treatment (ART) sealants and restorations: a meta-analysis. Clin Oral Investig. 2012;16(2):429-41. doi:10.1007/s00784-011-0513-3

27. Gil-Montoya JA, Mateos-Palacios R, Bravo M, González-Moles MA, Pulgar R. Atraumatic restorative treatment and Carisolv use for root caries in the elderly: 2-year follow-up randomized clinical trial. Clin Oral Investig. 2014;18(4):1089-95. doi:10.1007/s00784-013-1087-z

28. Mickenautsch S, Grossman E. Atraumatic Restorative Treatment (ART): factors affecting success. J Appl Oral Sci. 2006;14 Spe No:34-6. doi:10.1590/S1678-77572006000700008
29. Covey DA, Ewoldsen NO. Porosity in manually and machine mixed resin-modified glass ionomer cements. Oper Dent. 2001;26(6):617-23.

30. Mickenautsch S, Yengopal V, Banerjee A. Atraumatic restorative treatment versus amalgam restoration longevity: a systematic review. Clin Oral Investig. 2010;14(3):233-40. doi:10.1007/s00784-009-0335-8

31. Ewoldsen N, Covey D, Lavin M. The physical and adhesive properties of dental cements used for atraumatic restorative treatment. Spec Care Dentist. 1997;17(1):19-24. doi:10.1111/j.1754-4505.1997.tb00531.x

32. Lopez N, Simpser-Rafalin S, Berthold P. Atraumatic restorative treatment for prevention and treatment of caries in an underserved community. Am J Public Health. 2005;95(8):1338-9. doi:10.2105/AJPH.2004.056945

33. Franca C, Colares V, van Amerongen E. The operator as a factor of success in ART restorations. Braz J Oral Sci. 2011;10(1):60-4.

34. Kemoli AM, Amerongen WE. Effects of oral hygiene, residual caries and cervical Marginal-gaps on the survival of proximal atraumatic restorative treatment approach restorations. Contemp Clin Dent. 2011;2(4):318-23. doi:10.4103/0976-237X.91796

35. Francisconi LF, Graeff MS, Martins LM, Franco EB, Mondelli RF, Francisconi PA, et al. The effects of occlusal loading on the margins of cervical restorations. J Am Dent Assoc. 2009;140(10):1275-82. doi:10.14219/jada.archive.2009.0051 